\title{
Targeting Angiogenesis in Cancer Treatments: Where do we Stand?
}

\author{
Petrovic N.
}

School of Pharmacy and Medical Sciences, University of South Australia, Australia.

Received, April 11, 2016; Revised, May 23, 2016; Accepted, June 24, 2016; Published, June 26, 2016.

\begin{abstract}
Since early seventies of the twentieth century, through seminal work of Judah Folkman, angiogenesis, the process of new blood vessel sprouting from the existing vasculature, was recognized as a necessary part of wound healing, development of placenta, tissue growth and regeneration as well as cancer progression. This process is induced by low tissue oxygenation and it is a crucial prerequisite for rapid tissue growth, providing proper oxygen supply and removal of toxic metabolites. Suppression of angiogenesis as a way of slowing down tumor progression continues to be one of the most important areas of cancer research. The angiogenic process is relatively complex and it is regulated by numerous pro- and anti-angiogenic factors. Intensive research in the last twenty years resulted in identification of more than 300 angiogenesis inhibitors, a trend that is expected to continue. Unfortunately, most of these treatments have demonstrated unacceptable toxicities or failed to show activity in clinical studies. Although not yet completely understood, the complex process of tumor angiogenesis involves highly regulated orchestration of multiple activating and inhibiting factors. Vascular endothelial growth factor (VEGF) and its cognate receptors appear to play a central role in angiogenesis activation. Thus, initial efforts to develop anti-angiogenic treatments focused largely on inhibiting VEGF action. Such approaches, however, often lead to transient responses due to multiple pathways able to compensate for a single pathway inhibited. Accordingly, more recent treatments have focused on simultaneous inhibition of multiple signaling pathways. This review concentrates on identifying those antiangiogenic treatments that made to the clinic by receiving approval by USA Food and Drug Administration (FDA) as treatments for cancer. Regardless of observed problems, it is an imperative that research in angiogenesis regulation continues. Consequently, pharmacological manipulation of angiogenesis may yet to introduce truly new pharmacological therapies into the field of cancer therapy, the field that was rather dormant in the last several decades.
\end{abstract}

This article is open to POST-PUBLICATION REVIEW. Registered readers (see "For Readers") may comment by clicking on ABSTRACT on the issue's contents page.

\section{INTRODUCTION}

Formation of functional vasculature is the crucial prerequisite for growth and most of physiological processes in mammalian tissues. Proper supply with oxygen and nutrients, together with efficient removal of unwanted metabolites and $\mathrm{CO}_{2}$ are necessary for growth of the healthy tissues as well as tumors. It is estimated that growth of tissue to the sizes above $2-3 \mathrm{~mm}^{3}$ requires proper blood supply (1). During embryonic development blood vessels are created de novo from endothelial cell precursors (angioblasts) through the process called vasculogenesis (2). Vasculature formation during development is not the end of vascular network growth. Vascular tissue formation is highly dynamic process continuing well after cessation of development. Adjustment of vascular network coverage is continuously occurring throughout adult life and it is progressing by new blood vessel outgrowth from pre-existing capillaries in the process of angiogenesis (3). Such growth of new vasculature is usually quite limited since apart from growing tumors, relatively few adult tissues require ongoing angiogenesis. These include female reproductive organs, organs that are actively growing or tissue regenerating following injury (4). Transition from quiescent vascular state to active angiogenesis is termed "angiogenic switch". While vasculogenesis and angiogenesis have been considered to be distinct processes, they share many similarities. Thus, some evidence suggests that endothelial progenitors may contribute to vessel growth both in embryo and in ischemic and malignant adult tissues $(5,6)$.

Corresponding Author: Petrovic N, School of Pharmacy and Medical Sciences, University of South Australia, Adelaide, SA 5000, Australia; E-mail: Nenad.petrovic@unisa.edu.au 
However, the percentage of endothelial precursors incorporated into newly formed blood vessels during angiogenesis is generally low, supporting the concept that adult tissues and tumor neovascularization occurs primarily via the process of existing vessel sprouting (5).

In early tumor development, cancer cells are oxygenated through simple diffusion in a phase defined as "avascular state". Tumors of small size can remain dormant for many months after reaching a steady state between proliferation and apoptosis (7). The demand for oxygen and nutrients varies widely among tumors and it is often dependent upon tumor type, its stage of growth and its location. These physiological requirements could also change over the course of tumor progression (8). Tumor cells characteristically show a reduced oxygen dependency compared to normal cells, and are thought to sustain their metabolism under relatively anaerobic conditions by increasing glycolysis to maintain ATP production (so called Warburg effect) (9). However, despite their increased tolerance to hypoxia, tumors remain strictly dependent on adequate oxygen supply for their exponential growth. After initial acute oxygen deprivation and as growth progresses and the lack of oxygen becomes chronic. Induction of specific genes expression allows tumors to overcome hypoxia by increasing their blood supply through angiogenesis. This neovascularization signals the change from relatively dormant state to a tumor capable of rapid growth and metastasis. It is characterized by a set of physiological events termed the "angiogenic switch" which is provoked by a change in balance of pro- and anti-angiogenic molecules (4). In addition to physiological stimuli, factors influencing the angiogenic switch include genetic mutations, metabolic and mechanical stress, inflammation and activation of oncogenes and/or inactivation of tumor-suppressor genes (10, 11). Factors affecting the onset of the angiogenic switch may be tumor and tissue-specific and may also change during tumor progression $(12,13)$. The switch can occur at different stages of tumor growth, again depending on the type of the tumor and the surrounding tissue. Angiogenesis will continue as long as the tumor grows and demand for oxygen and nutrients by the hypoxic and necrotic areas of the tumor exists. Furthermore, angiogenesis is a crucial process that impacts not only malignant tumor growth, but also increases tumor metastasis (13).

This review aim is to summarize current status of angiogenesis suppressive therapies through identifying those treatments that made to the clinic by receiving approval by USA Food and Drug Administration (FDA) as treatments for cancer. Also, limitations of such therapy are outlined, as well as some new directions. Regardless of significant complications encountered in application of such therapies, angiogenesis suppression is still an important new addition to the classical cancer treatments that did not include any new pharmacological options in the past several decades.

\section{Angiogenesis phases}

The process of angiogenesis progresses through several distinct stages (Diagram 1). It begins with perivascular detachment and vessel dilation (Diagram 1B) in the vicinity of the tissue affected by hypoxia, followed by disassembly of existing blood vessel into individual activated endothelial cells and pericytes (14). Pericytes are cells embedded within the basement membrane of small blood vessels. Their major function appears to be reinforcing and stabilization of vascular structure to achieve proper microvascular blood flow. Activated pericytes and endothelial cells participate in digestion of basal lamina by releasing proteases (Diagram 1C). Interaction between endothelial cells and extracellular matrix appears to be crucial for proper endothelial angiogenic activation (15). Angiogenic process continues through division and migration of endothelial cells and pericytes toward the hypoxic tumor (Diagram 1D), followed by assembly and differentiation of endothelial cells into the new blood vessel (Diagram 1E). The process is finalized by establishment of new vascular connection between primary vessel and tumor. This is achieved by maturation and renewed recruitment of pericites to the newly formed blood vessel (Diagram 1F). Successful completion of each of these steps is required for the final formation of the functional new blood vessels.

\section{Regulation of angiogenesis}

Major signal for initiation of angiogenesis is tissue or tumour hypoxia and subsequent decrease in oxidative metabolism and ATP production (16). Intracellular induction of hypoxia-inducible factors (HIFs) appear to be crucial for transcriptional induction of genes that mediate subsequent angiogenic steps. HIFs are constantly expressed and degraded under normoxia, but stabilized under hypoxia (17). 


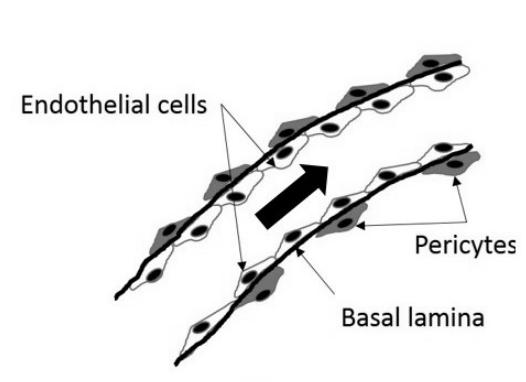

A

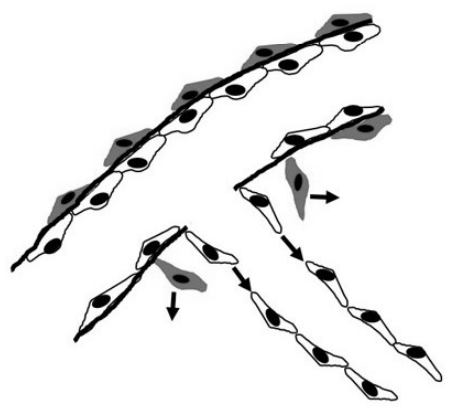

D

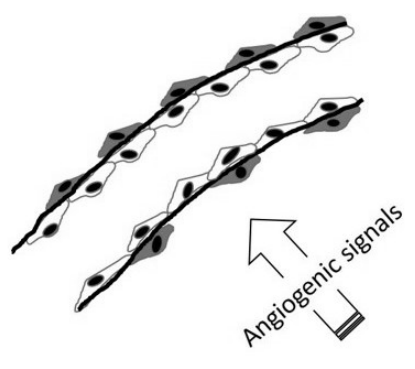

B

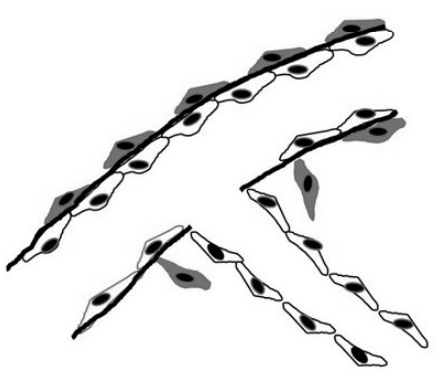

E

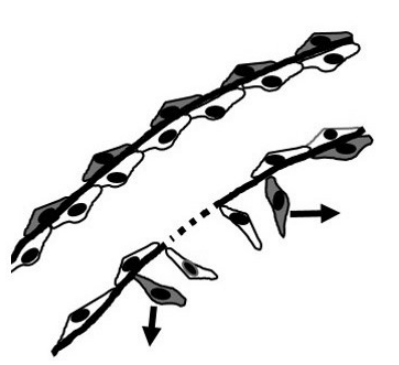

C

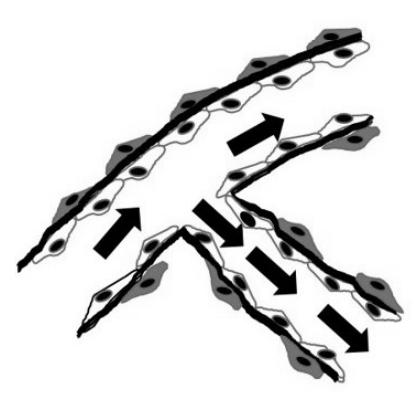

$\mathbf{F}$

Diagram 1: Stages of tumor angiogenesis

Specifically, HIF-2 $\alpha$ has the major role in vascular remodelling through angiogenesis (17). As a consequence of HIFs induction in tissues affected by hypoxia, numerous humoral factors are released from affected tissue to initiate functional changes in neighbouring vasculature leading to angiogenesis (18).

Hypoxia-inducible factor-1 $\alpha$ (HIF-1 $\alpha)$ induced expression and release of vascular endothelial growth factor (VEGF) and basic fibroblast growth factor (bFGF) during tissue and tumor hypoxia plays the most important part in activation of vascular endothelial cells and initiation of angiogenesis process $(19,20)$.

In order to respond to these signals, vascular endothelial cells express corresponding receptors. VEGF is not a single factor but a relatively large family of growth factors. VEGF-A is the prototypical member of a family that includes placental growth factor (PLGF), VEGF-B, VEGF$\mathrm{C}$, and VEGF-D (also known as c-Fos-induced growth factor, FIGF) (21). In that family, VEGF-A appears to be the main regulator of angiogenesis. VEGF-A is not a single protein, but a group of three major isoforms resulting from alternative splicing of mRNA from a single, 8-exon VEGFA gene. Such process is producing three isoforms (VEGFA120, VEGFA164, and VEGFA188) all of them physiologically active. VEGF-A family binds to two tyrosine-kinase receptors: VEGF receptor 1 (VEGFR-1 also known as flt-1) and VEGF receptor 2 (VEGFR-2, also called KDR/Flk-1), which are expressed almost exclusively in endothelial cells $(22,23)$. VEGF-A has been shown to be the necessary factor in angiogenesis induction. It stimulates endothelial cell mitogenesis, cell migration and expression of genes that regulate angiogenic switch (24).

Similarly to VEGF, physiological effects of fibroblast growth factors (FGFs) are mediated by four structurally related receptor tyrosine kinases, denoted FGFR-1, -2, -3 and -4 , which display broad expression patterns. FGFs are important angiogenic growth factors, and basic FGF (bFGF or FGF2) is recognized as a potent inducer of angiogenesis $(25,26)$.

In addition to growth factors, interaction of endothelial cells with extracellular matrix appears to be crucial for proper regulation of angiogenesis. Major constituents of extracellular matrix are structural proteins such as laminin, entactin, collagen and heparan sulfate proteoglycans (27). Cell adhesion to such complex substrate is essential for the expression of numerous endothelial genes and differentiation of endothelial cells during angiogenesis. Importance of matrix- 
endothelial integrin interaction in angiogenesis has been well-documented (28).

Considering that angiogenesis is heavily regulated sequential set of events and that its progression is dependent on successful completion of each of the proceeding steps, it is not surprising that there are many endogenous factors that could stop or slow down the whole process (29 and Table $1)$.

Consequently, blocking of excessive pathological angiogenesis could be theoretically achieved by either increasing activity of endogenous inhibitors or blocking the action of angiogenesis activators. Endogenous inhibitors of angiogenesis include interferons $(\alpha, \beta$ and $\gamma$ ) which act by decreasing expression of angiogenesisactivators (30) such as bFGF or induce apoptosis of endothelial cells (31); Interleukin 12 promotes apoptosis of endothelial cells (32) whereas interleukin-10 down-regulates synthesis of VEGF and matrix metalloproteinase 9 (MMP-9) (33); Tissue inhibitor of matrix metalloproteinase (TIMP), inhibits degradation and remodelling of extracellular matrix which is necessary for efficient endothelial cells migration and proliferation (34, 35); Angiostatin, a $38 \mathrm{KDa}$ internal fragment of plasminogen, down-regulates VEGF expression and suppresses endothelial proliferation and migration (36-38); Endostatin, a $20 \mathrm{KDa}$ fragment of type XVIII collagen blocks action of VEGF (39); Pigment epithelium-derived factor (PEDF) inhibits endothelial migration and proliferation (40); Vasostatin, a 180 amino acid calreticulin fragment, inhibits endothelial cell proliferation (41); Kringle 5 fragment of human plasminogen induces apoptotic death of endothelial cells (42); Thrombospondin-1 is a glycoprotein that influences cellular phenotype and the structure of the extracellular matrix. It inhibits angiogenesis through direct effects on endothelial migration and survival and through indirect effects on growth factor mobilization (43); Chondromodulin-I (ChM-I), a 25-kDa glycoprotein in cartilage matrix secreted from chondrocytes into the extracellular matrix inhibits endothelial migration (44).

Unfortunately, there are no clinical treatments or drugs developed based on those endogenous inhibitors of angiogenesis apart from interferon- $\alpha$. Potential reasons for such outcomes could reside in the fact that peptide drug treatments are extremely difficult to design and implement. Furthermore patient treatment with interferons and cytokines has been plagued with significant systemic adverse effects and unacceptable high toxicity (45).

Table 1. Endogenous inhibitors of angiogenesis

\begin{tabular}{|c|c|c|}
\hline Interferons $(\alpha, \beta$ and $\gamma)$ & $\begin{array}{l}\text { Mechanism of action } \\
\text { Downregulate angiogenesis stimulators } \\
\text { synthesis and inhibit cell migration of EC }\end{array}$ & Reference \\
\hline Interleukins (10 and 12) & $\begin{array}{l}\text { Stimulate angiogenesis inhibitor } \\
\text { formation }\end{array}$ & 32,33 \\
\hline $\begin{array}{l}\text { Tissue inhibitor of matrix } \\
\text { metalloproteinases (TIMPs) }\end{array}$ & $\begin{array}{l}\text { Increase apoptosis and decreases } \\
\text { proliferation of EC } \\
\text { Block binding of VEGF to KDR/Flk-1 }\end{array}$ & 34,35 \\
\hline Angiostatin & $\begin{array}{l}\text { Inhibits cell proliferation and induce } \\
\text { apoptosis of EC }\end{array}$ & $36,37,38$ \\
\hline Endostatin & $\begin{array}{l}\text { Increases apoptosis and decreases } \\
\text { proliferation of EC } \\
\text { Blocks binding of VEGF to KDR/Flk-1 }\end{array}$ & 39 \\
\hline PEDF, serine protease & $\begin{array}{l}\text { Decreases EC proliferation } \\
\text { Decreases proliferation of EC }\end{array}$ & 40 \\
\hline Vasostatin & $\begin{array}{l}\text { Decreases expression of angiogenesis } \\
\text { initiator Ang-2 } \\
\text { Decreases migration of EC }\end{array}$ & 41 \\
\hline Plasminogen kringle 5 & Increases apoptosis of EC & 42 \\
\hline Thrombospondin & $\begin{array}{l}\text { Inhibits binding of angiogenesis } \\
\text { stimulators to EC, EC migration, } \\
\text { proliferation, adhesion and survival }\end{array}$ & 43 \\
\hline $\begin{array}{l}\text { Chondromodulin-I (ChM-I), a } \\
\text { cartilage-derived angiogenesis }\end{array}$ & & \\
\hline
\end{tabular}


Consequently, design of new treatments aimed at blocking angiogenesis through suppressing

VEGF action are currently the main objective in clinical anti-angiogenesis research (46).

Currently available anti-angiogenic drugs have shown to result in only limited clinical benefits. Findings in early clinical studies suggest that decrease in dynamic of cancer progression could be achieved, but overall patient survival is in most cases unaffected. Furthermore, when tested in early stage cancers, there seems to be no benefit of angiogenesis inhibitors, possibly due to the low angiogenic potential of tumors at this stage (47). As the discovery of numerous new molecules with angiogenesis suppressive action grows, many new potential treatments have been proposed. The following examples are just some of the new research directions that deviate from the standard approaches outlined above.

A newly-developed vaccination treatment consisting of inducing an immune response against the tumor vasculature combines the benefits of immunotherapy and angiogenesis suppression and may overcome the limitations of current antiangiogenic drugs (48). Such therapy relies on the fact that active angiogenesis is usually absent in adults, thus minimizing potential adverse effects. Most studies have focused on VEGF as a target for active immunization in animal models, although attempts were also made to use glutaraldehydefixed endothelial cells as antigens in three malignant brain tumor patients and showed partial or complete tumor responses (49). Further studies in that direction are certainly needed to fully assess validity of such therapy.

Another example is the use of small interfering RNA (siRNA) to inhibit specific molecular targets involved in activation of angiogenesis. SiRNA, sometimes known as short interfering RNA or silencing RNA, is a class of double-stranded RNA molecules, 20-25 base pairs in length designed specifically to bind to and cause degradation of mRNA of specific gene targets. For example, siRNA suppressing expression of survivin was tested for its effects on angiogenesis in vitro. Survivin is a member of the inhibitor of apoptosis family. It inhibits caspase activation, thereby leading to suppression of apoptosis or programmed cell death. Blocking of survivin expression is found to have effects in cancer and endothelial cells, causing inhibited proliferation and apoptosis (50).

Furthermore, many agents from Chinese herbal medicines have shown powerful anti- angiogenic activities against tumor in in vitro and animal studies (51).

Regardless of these exciting new findings of new anti-angiogenesis factors, none of those treatments ever successfully passed clinical trials and their clinical potential is yet to be tested.

While cancer therapy aimed at suppressing angiogenesis in solid tumors is relatively easy to conceptualize, role of that therapy in blood cancers (various types of leukemia) is much more difficult to understand. Since all white blood lineage cells are produced in bone marrow, higher requirement for oxygen in bone marrow during increased production of blast cells in leukemic conditions could be the connection to solid tumor angiogenesis. Pronounced vascularization in pathologically increased function of bone marrow during leukemia is well documented. In these conditions, as in augmented requirement for new vasculature in growing solid tumors, bone marrow angiogenesis appears to be a prerequisite for increased production of blast cells in leukemia. Despite bone marrow high degree of vascularization, endosteal surface of cortical bone appears to be among the most hypoxic areas in the body (52). Consequently, numerous clinical trials are underway to determine efficacy of antiangiogenic treatments in various hematological malignancies (53). There is emerging evidence that progression of multiple myeloma, acute leukemia and myeloproliferative neoplasms depends on new blood vessel formation. Several agents aimed at blocking angiogenesis, like monoclonal antibodies, receptor tyrosine kinase inhibitors, immunomodulatory drugs have been entered in clinical trials or have been approved for treatment of these cancers. Multiple myeloma was the first hematological malignancy in which increased angiogenesis rate was detected (54) and it was shown that in this condition extent of bone marrow angiogenesis represents a good prognostic predictor since it is positively correlated with severity of the blood-born malignancies (55). Thus, it was demonstrated that bone marrow of acute lymphoblastic leukemia patients had increased blood vessel content compared to normal counterparts. Moreover, urine and peripheral blood samples from acute lymphoblastic leukemia patients contained elevated levels of proangiogenic growth factors, namely bFGF and VEGF, which correlated with the increase of bone marrow angiogenesis (56). In support of the role of pro-angiogenic factors in development of blood cancers, significantly increased bone marrow microvascular density and VEGF expression was 
found in patients with myeloproliferative neoplasms (57). Similarly, increased VEGF production and VEGF receptor expression was detected in three leukemic cell lines (HL-60, HEL, and K562) and primary leukemia samples. Injection of neutralizing monoclonal antibody specific to human VEGFR-2 into mice with transplanted human leukemia cells inhibited their proliferation of and significantly prolonged animal survival (58). It appears that regardless of leukemia type, increased microvascular density in bone marrow is always an indicator of disease severity. Similar observations were reported in bone marrow of patients with multiple myeloma, acute lymphoblastic leukemia, acute myeloid leukemia, myelodysplastic and myeloproliferative syndrome (59). Thus, a positive correlation between micro vessel score expression of VEGF and bFGF RNA in bone marrow blast cells in acute myeloid leukemia patients' was detected (60). Such changes correlate with extent of bone marrow hypoxia. Thus, elevated expression of VEGF correlated with Hif- $1 \alpha$ levels in B cell chronic lymphocytic leukemia (61). Increased response to proangiogenic factors is not restricted just to bone marrow vasculature, since the ability of leukemia cells to directly respond to angiogenic factors through expression of VEGF and VEGFRs have also been reported $(62,63)$.

These findings, taken together, suggest that anti-angiogenic therapy could become a part of clinical protocols for many leukaemia types and it is reasonable to expect new developments in that direction $(64,65)$. In addition, changes in expression of angiogenesis-related markers could become important prognostic tool in assessing disease severity and progression $(66,67)$.

\section{Current clinical application of anti-angiogenic treatment}

The anti-angiogenic therapy currently being approved for clinical use include: (1) direct antiVEGF treatments to include anti-VEGF, antiVEGFR antibodies and VEGF "traps"; (2) immunomodulatory drugs with antiangiogenic properties and (3) receptor tyrosine kinase inhibitors, targeting VEGF receptors and their signalling (Diagram 2). Apart from those therapies, a large number of potential anti-angiogenic therapies are currently at the research stage (68). The major problem associated with therapy aimed to suppress angiogenesis and ultimately block tumour growth and development is transient improvement in patient condition but not overall survival compared to chemotherapy alone. Future research is expected to optimize the antiangiogenic therapy that would be successfully combined with traditional treatments.

The following drug classes of angiogenesis inhibitors are currently approved by the U.S. Food and Drug Administration (FDA) to treat cancerous conditions. Typically, these drugs are given together with main types of cancer treatment, such as chemotherapy. In the U.S., there are currently fifteen approved anti-cancer therapies with recognized antiangiogenic properties (USA Angiogenesis Foundation (http://www.angio.org/) all falling into the six categories based on their mechanism of action. Diagram 2 summarizes mode of action of the currently approved drugs.

\section{Endothelium-specific drugs}

Cumulative information about mechanism of action of these drugs is given in Diagram 2.

\section{Anti-VEGF and anti-VGFR antibodies}

Bevacizumab (Avastin) is a monoclonal antibody against VEGFA (69). It blocks the interaction of VEGF to its receptors (Flt-1 and KDR) on the surface of endothelial cells. It is approved for treatment of colorectal, kidney and lung cancer. As an antibody, it is given intravenously. After a series of clinical trials in 2004, Avastin was approved by the FDA, becoming the first commercially available anti-angiogenesis drug. FDA approval of Avastin for breast cancer treatment was later revoked in 2011 due to lack of effectiveness and required safety, although bevacizumab still remains on the market as approved treatment for certain types of colon, lung, kidney and brain cancers (70).

Ramucirumab (Cyramza) is a monoclonal antibody directed against VEGFR-2 and it is approved for treatment of advanced stomach cancers and gastroesophageal junction adenocarcinoma (71). As an antibody, it is applied intravenously.

\section{VEGF "traps"}

Aflibercept (Zaltrap) binds to circulating VEGFs and acts like a "VEGF trap" (72). It inhibits the activity of both VEGF-A and VEGF-B.

\section{Drugs affecting endothelium as well as other tissues}

1. mTOR inhibitors

Everolimus (Afinitor) is a derivative of sirolimus (also known as rapamycin, a macrolide produced by the bacterium Streptomyces hygroscopicus) an inhibitor of mammalian target of rapamycin (mTOR), also known as FK506-binding protein 
and 12-rapamycin-associated protein 1 (FRAP1). It is a serine/threonine protein kinase that regulates cell growth, cell proliferation, motility, survival, protein synthesis, autophagy, and gene transcription (73). It belongs to the phosphatidylinositol 3-kinase-related kinase protein family. Sirolimus has immunosuppressant functions in humans and is used to prevent rejection after organ transplantation and suppress activation of $\mathrm{T}$ and $\mathrm{B}$ cells by inhibiting production of interleukin-2. It is taken orally. As a general immunosuppressant and action relatively nonspecific to angiogenesis, everolimus is shown to possess expected adverse effects characteristic of immunosuppressant drugs (74). Temsirolimus (Torisel) acts through its active metabolite sirolimus, binds to an intracellular protein (FKBP12), form a protein-drug complex inhibiting the activity of mTOR that controls cell division (75).

\section{Interferon- $\alpha$}

Interferon-alpha (IFN- $\alpha$ ) has anti-angiogenic properties in addition to its immune-stimulatory and anti-proliferative effects. IFN- $\alpha$ has been shown to inhibit angiogenesis through downregulation of bFGF expression in murine cancer models $(76,77)$. In clinical testing, administration of bevacizumab with IFN- $\alpha$ led to a clinical response in $24 \%$ of patients with stage IV melanoma and stabilization of disease in another $20 \%$ of patients (78).

\section{Small molecule receptor tyrosine kinase inhibitors}

There are currently seven receptor tyrosine kinase inhibitors approved for cancer treatment. Although both VEGFR and bFGFR are tyrosine kinase receptors and are inhibited by those drugs, many other growth factor receptors are of the same kind, making the treatment with receptor tyrosine kinase inhibitors relatively non-specific to angiogenesis.

Axitinib (Inlyta) is an approved option to treat kidney cancer (79). Phase III data validated sunitinib, pazopanib and sorafenib as the bestsupported drugs in first line therapy for treatment of metastatic renal cell carcinoma, whereas second-line treatment possibilities include axitinib, everolimus and sorafenib (80).

Cabozantinib (Cometriq) a small molecule inhibitor of the tyrosine kinases c-Met and VEGFR2 is currently approved for use in medullary thyroid cancer treatment (81).

Pazopanib (Votrient) is approved for treatment of kidney cancer and advanced soft tissue sarcoma. It is an orally-active drug and multi-target receptor tyrosine kinase inhibitor that blocks tumor growth and inhibits angiogenesis (82). Its main targets are c-KIT, FGFR, PDGFR and VEGFR.

Regorafenib (Stivarga) is an oral multi-kinase inhibitor which targets angiogenic, stromal and oncogenic receptor tyrosine kinases. It shows antiangiogenic activity due to its dual VEGFR2-TIE2 tyrosine kinase inhibition (83).

Sorafenib (Nexavar) is an inhibitor of receptor tyrosine kinases (VEGFR and PDGFR) and Raf kinases (84). Platelet-derived growth factor receptors (PDGFRs) are cell membrane tyrosine kinase receptors for members of the plateletderived growth factor (PDGF) family. PDGFRs regulates cellular proliferation, differentiation and growth in many tissues. Sorafenib has broad mechanism of action, including suppression of angiogenesis. It is taken orally (85).

Sunitinib (Sutent) previously known as SU11248 is a small-molecule oral drug and multitargeting receptor tyrosine kinase inhibitor of intracellular signaling. Targets include all receptors for platelet-derived growth factor (PDGFRs) and vascular endothelial growth factor (VEGFRs), which play a role in both tumor angiogenesis and tumor cell proliferation (86). The simultaneous inhibition of these targets reduces tumor vascularization and triggers cancer cell apoptosis (87).

Vandetanib (Caprelsa) is used for the treatment of medullary thyroid cancer. It acts as a kinase inhibitor of a number of cell receptors, mainly the VEGFR, epidermal growth factor receptor (EGFR) and the RET-tyrosine kinase family (88).

4. Immune-suppressive and antiinflammatory drugs

Lenalidomide (Revlimid) is used to treat multiple myeloma. It is an orally active drug with immunomodulatory, anti-angiogenic, and direct apoptotic properties causing cancer cell apoptosis (89). While recent preclinical and clinical studies put forward a dual mechanism of its action involving both direct anti-tumor activity as well as immunomodulation, it is presently unclear which mechanism(s) are responsible for its effectiveness.

Thalidomide (Thalomid) is an immunomodulatory drug. Its precise mechanism of action is currently unknown. Possible mechanisms include tissue anti-angiogenic and oxidative stressinducing effects (90). It also inhibits TNF- $\alpha$, IL-6, IL-10 and IL-12 production, modulates the production of IFN- $\gamma$ and enhances the production of IL-2, IL-4 and IL-5 by immune cells (91). It is highly teratogenic oral drug. 


\section{Current limitations of angiogenesis-suppressing cancer therapy}

Existing preclinical and clinical investigations clearly indicate transient efficacy of current antiangiogenic drugs where tumorigenesis resumes after withdrawal of therapy. Consequently, the impact of current angiogenesis suppressing therapies on overall patient survival has been somewhat disappointing primarily due to development of drug resistance (92-98). One of the potential reasons for those observations might be related to the discovery of numerous compensatory vascular mechanisms existing in tumors. Those mechanisms allow tumors to become relatively resistant to angiogenesis-suppression therapy (92). In addition, new vascular remodeling processes have been identified that are relatively angiogenesis-independent (93). These include vessel co-option (growth without angiogenesis through "recruiting" of pre-existing vessels (94), intussusception (occurring by internal division of the pre-existing capillary network without sprouting) (95) and vascular mimicry (where cancer cells form vessel-like structures able to transport blood) (96). It was estimated that up to $30 \%$ of tumors possess ability to use these alternative ways to insure adequate blood supply (97). Taking into account growing number of anticancer agents directed toward suppressing vascular growth, identification of factors causing observed drug resistance is of great importance (98).

The second hurdle of anti-angiogenic therapy is its toxicity predominantly related to drug targets. It is important to emphasize that such toxic effects are usually milder compared to the classic cytostatic therapy. Considering that bevacizumab is one of the first angiogenesis suppressive therapies approved for inclusion into cancer treatment protocols, it is not surprising that it is the most investigated drug compared to the rest of currently available options. Consequently adverse drug effects of those treatments are reported the most. Thus, both bevacizumab and VEGFR kinase inhibitors have been shown to cause hypertension and these toxicities correlate with the response (99). In the study using FOLFIRI protocol (folinic acid, 5-fluorouracil and irinotecan) combined with bevacizumab as a first-line treatment for colorectal cancer, grade 3/4 toxicities were reported (grade 3 is classified as severe and grade 4 as life- threatening) to include neutropenia (16.1\%), diarrhea (11.3\%) and nausea-vomiting (1.6\%) (100). Based on those findings, authors concluded that such treatment has good safety profile compared to existing chemotherapy protocols and could be used in clinical setting. Furthermore, current experience with angiogenesis inhibitors in clinical trials indicates that observed short-term toxicities are mostly manageable (101). In addition, reported adverse effects do not happen with every drug or with every patient. Rarely, those effects could be more serious, to include serious bleeding, heart attacks, heart failure or thrombosis (102). Another rare side effects include bowel mucosal damage induced by chemotherapy that may be exacerbated by treatment with bevacizumab, resulting in extensive necrosis (103). Regardless of the observed side effects, most of therapies aimed at suppression of tumor angiogenesis exhibited acceptable safety profile, particularly when compared to standard cytotoxic protocols (104).

\section{CONCLUSIONS}

From its discovery, more than forty years ago, angiogenesis is considered one of the most promising new targets in pharmacological treatment of various types of cancer. Taking into account that growth and metastatic potential of any cancer are very dependent on proper tumor vascularization, the possibility to suppress angiogenesis in cancer treatment generated significant excitement in the field.

Today, after accumulated knowledge about angiogenesis and its regulation we have all realized that the process itself appears to be much more complex than previously thought. Consequently, although angiogenesis remains an important target for new treatments, current expectations regarding success of such therapy are somewhat lowered. Currently, combinatory anti-angiogenesis treatments are investigated in many clinical studies and that direction (at least in short term) is expected to continue (reviewed in 105-107). Regardless of observed complications, angiogenesis suppression is still an extremely important addition to the cancer treatment, which did not include any new pharmacological options for the past several decades. 


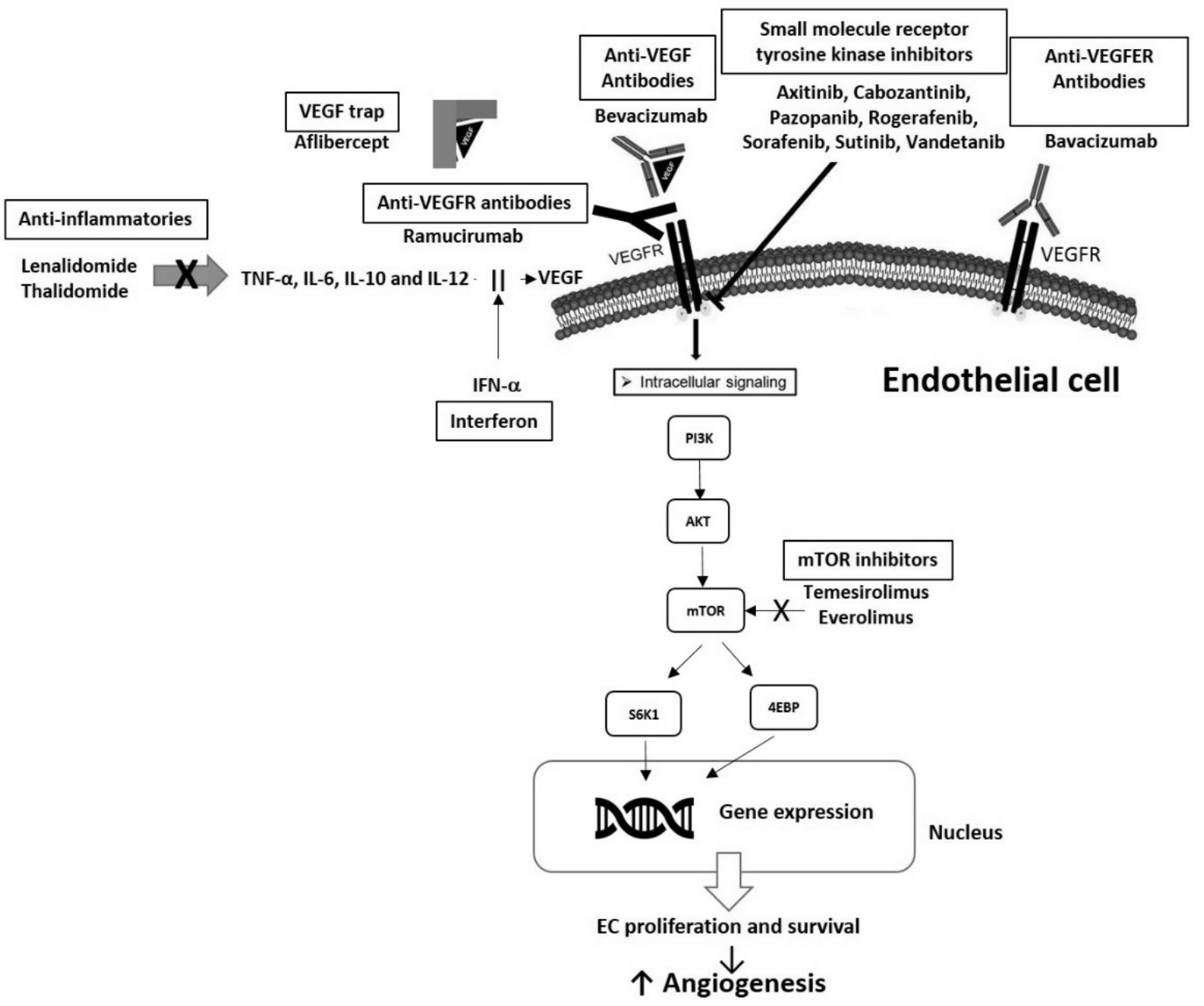

Diagram 2. Mode of action of current FDA approved anti-angiogenic drugs

\section{REFERENCES}

1. Folkman J. Tumor angiogenesis: therapeutic implications. N Engl J Med 1971;285:1182-1186

2. Ribatti D, Nico B, Crivellato E. The development of the vascular system: a historical overview. Methods Mol Biol 2015;1214:1-14

3. Carmeliet P. Mechanisms of angiogenesis and arteriogenesis. Nat Med 2000;6:389-395

4. Hanahan D, Folkman J. Patterns and emerging mechanisms of the angiogenic switch during tumorigenesis. Cell 1996;86:353-364

5. Lyden D, Hattori K, Dias S, Costa C, Blaikie P, Butros L, Chadburn A, Heissig B, Marks W, Witte L, Wu Y, Hicklin D, Zhu Z, Hackett NR, Crystal RG, Moore MA, Hajjar KA, Manova K, Benezra $\mathrm{R}$, Rafii S. Impaired recruitment of bone-marrow derived endothelial and hematopoietic precursor cells blocks tumor angiogenesis and growth. Nat Med 2001;7:1194-1201

6. Rafii S, Heissig B, Hattori K. Efficient mobilization and recruitment of marrow derived endothelial and hematopoietic stem cells by adenoviral vectors expressing angiogenic factors. Gene Ther 2002;9:631-641

7. Black WC, Welch HG. Advances in diagnostic imaging and overestimations of disease prevalence and the benefits of therapy. N Engl J Med 2002;328:1237-1243

8. Hlatky L, Hahnfeldt P, Folkman J. Clinical application of antiangiogenic therapy: microvessel density, what it does and doesn't tell us. J Natl Cancer Inst 2002;94:883-893

9. Papetti M, Herman IM. Mechanisms of normal and tumor-derived angiogenesis. Am J Physiol Cell Physiol 2002;282:C947-C970

10. Kerbel R, Folkman J. Clinical translation of angiogenesis inhibitors. Nat Rev Cancer 2002;2:727-739

11. Carmeliet P, Jain RK. Angiogenesis in cancer and other diseases. Nature 2002;407:249-257

12. Folkman J. Looking for a good endothelial address. Cancer Cell 2002;1:113-115 
13. Dor Y, Porat R, Keshet E. Vascular endothelial growth factor and vascular adjustments to perturbations in oxygen homeostasis. Am J Physiol Cell Physiol 2001;280:C1367-C1374

14. van Dijk CG, Nieuweboer FE, Pei JY, Xu YJ, Burgisser $\mathrm{P}$, van Mulligen $\mathrm{E}$, el Azzouzi $\mathrm{H}$, Duncker DJ, Verhaar MC, Cheng C. The complex mural cell: pericyte function in health and disease. Int J Cardiol 2015;190:75-89

15. Hoang KG, Allison S, Murray M, Petrovic N. Prostanoids regulate angiogenesis acting primarily on IP and EP4 receptors. Microvasc Res 2015;101:127-134

16. Fraisl P, Mazzone M, Schmidt T, Carmeliet P. Regulation of angiogenesis by oxygen and metabolism. Dev Cell 2009;16:167-179

17. Hashimoto T, Shibasaki F. Hypoxia-inducible factor as an angiogenic master switch. Front Pediatr 2015;3: 33

18. Ruas JL, Lendahl U, Poellinger L. Modulation of vascular gene expression by hypoxia. Curr Opin Lipidol 2007; 18:508-514

19. Saponaro C, Malfettone A, Ranieri G, Danza K, Simone G, Paradiso A, Mangia A. VEGF, HIF-1 $\alpha$ expression and MVD as an angiogenic network in familial breast cancer. PLoS One 2013;8(1):e53070

20. Bos R, van Diest PJ, de Jong JS, van der Groep P, van der Valk $P$, van der Wall E. Hypoxiainducible factor-1alpha is associated with angiogenesis, and expression of bFGF, PDGF-BB, and EGFR in invasive breast cancer. Histopathology 2005;46:31-36

21. Hoeben A, Landuyt B, Highley MS, Wildiers H, Van Oosterom AT, De Bruijn EA. Vascular endothelial growth factor and angiogenesis. Pharmacol Rev 2004;56:549-580

22. Waltenberger J, Claesson-Welsh L, Siegbahn A, Shibuya M, and Heldin CH. Different signal transduction properties of KDR and Flt1, two receptors for vascular endothelial growth factor. J Biol Chem 1994;269:26988-26995

23. Szymczak M, Murray M, Petrovic N. Modulation of angiogenesis by omega-3 polyunsaturated fatty acids is mediated by cyclooxygenases. Blood 2008;111:3514-3521

24. Lee SH, Jeong D, Han YS, Baek MJ. Pivotal role of vascular endothelial growth factor pathway in tumor angiogenesis. Ann Surg Treat Res 2015;89:1-8

25. Przybylski M. A review of the current research on the role of bFGF and VEGF in angiogenesis. J Wound Care 2009; 18:516-519

26. Cross MJ, Claesson-Welsh L. FGF and VEGF function in angiogenesis: signalling pathways, biological responses and therapeutic inhibition. Trends Pharmacol Sci 2001;22:201-207

27. Kleinman HK, Martin GR. Matrigel: Basement membrane matrix with biological activity. Semin Cancer Biol 2005; 15:378-386
28. Doron DA, Jacobowitz DM, Heldman E, Feuerstein G, Pollard HB, Hallenbeck JM. Extracellular matrix permits the expression of von Willebrand's factor, uptake of di-I-acetylated low density lipoprotein and secretion of prostacyclin in cultures of endothelial cells from rat brain microvessels. In Vitro Cell Dev Biol 1991;27A:689-697

29. Ribatti D, Conconi MT, Nussdorfer GG. Nonclassic endogenous novel regulators of angiogenesis. Pharmacol Rev 2007;59:185-205

30. Slaton JW, Perrotte P, Inoue K, Dinney CP, Fidler IJ. Interferon-alpha-mediated down-regulation of angiogenesis-related genes and therapy of bladder cancer are dependent on optimization of biological dose and schedule. Clin Cancer Res 1999;5:27262734

31. Jonasch E, Haluska FG. Interferon in oncological practice: review of interferon biology, clinical applications, and toxicities. Oncologist 2001;6:3455

32. Duda DG, Sunamura M, Lozonschi L, Kodama T, Egawa S, Matsumoto G, Shimamura H, Shibuya K, Takeda K, Matsuno S. Direct in vitro evidence and in vivo analysis of the antiangiogenesis effects of interleukin 12. Cancer Res 2000;60:1111-1116

33. Huang S, Ullrich SE, Bar-Eli M. Regulation of tumor growth and metastasis by interleukin-10: the melanoma experience. J Interferon Cytokine Res 1999;19:697-703

34. Fernandez HA, Kallenbach K, Seghezzi G, Grossi E, Colvin S, Schneider R, Mignatti P, Galloway A. Inhibition of endothelial cell migration by gene transfer of tissue inhibitor of metalloproteinases1. J Surg Res 1999;82:156-162

35. Murphy AN, Unsworth EJ, Stetler-Stevenson WG. Tissue inhibitor of metalloproteinases-2 inhibits bFGF-induced human microvascular endothelial cell proliferation. J Cell Physiol 1993;157:351-358

36. Hajitou A1, Grignet C, Devy L, Berndt S, Blacher S, Deroanne CF, Bajou K, Fong T, Chiang Y, Foidart JM, Noël A. The antitumoral effect of endostatin and angiostatin is associated with a down-regulation of vascular endothelial growth factor expression in tumor cells. FASEB J 2002;16:1802-1804

37. Moser TL1, Stack MS, Asplin I, Enghild JJ, Højrup P, Everitt L, Hubchak S, Schnaper HW, Pizzo SV. Angiostatin binds ATP synthase on the surface of human endothelial cells. Proc Natl Acad Sci U S A. 1999;96:2811-2816

38. Griscelli F, Li H, Bennaceur-Griscelli A, Soria J, Opolon P, Soria C, Perricaudet M, Yeh P, Lu H. Angiostatin gene transfer: inhibition of tumor growth in vivo by blockage of endothelial cell proliferation associated with a mitosis arrest. Proc Natl Acad Sci U S A. 1998;95:6367-6372

39. Kim YM1, Hwang S, Kim YM, Pyun BJ, Kim TY, Lee ST, Gho YS, Kwon YG. Endostatin blocks 
vascular endothelial growth factor-mediated signaling via direct interaction with $\mathrm{KDR} / \mathrm{Flk}-1$. J Biol Chem 2002;277:27872-27879

40. Loegl J, Nussbaumer E, Hiden U, Majali-Martinez A, Ghaffari-Tabrizi-Wizy N, Cvitic S, Lang I, Desoye G, Huppertz B. Pigment epitheliumderived factor (PEDF): a novel trophoblastderived factor limiting feto-placental angiogenesis in late pregnancy. Angiogenesis. 2016; [Epub ahead of print]

41. Maestroni S, Maestroni A, Ceglia S, Tremolada G, Mancino M, Sacchi A, Lattanzio R, Zucchiatti I, Corti A, Bandello F, Zerbini G. Effect of chromogranin A-derived vasostatin-1 on laserinduced choroidal neovascularization in the mouse. Acta Ophthalmol 2015;93:e218-22

42. Cai WB, Zhang Y, Cheng R, Wang Z, Fang SH, Xu ZM, Yang X, Yang ZH, Ma JX, Shao CK, Gao GQ. Dual inhibition of plasminogen kringle 5 on angiogenesis and chemotaxis suppresses tumor metastasis by targeting HIF-1 $\alpha$ pathway. PLoS One. 2012;7:e53152

43. Pinessi D, Foglieni C, Bugatti A, Moroni E, Resovi A, Ribatti D, Rusnati M, Giavazzi R, Colombo G, Taraboletti G. PO-15 Antiangiogenic small molecule ligands of FGF2 derived from the endogenous inhibitor thrombospondin-1. Thromb Res. 2016;140 Suppl 1:S182

44. Miura S, Mitsui K, Heishi T, Shukunami C, Sekiguchi K, Kondo J, Sato Y, Hiraki Y. Impairment of VEGF-A-stimulated lamellipodial extensions and motility of vascular endothelial cells by chondromodulin-I, a cartilage-derived angiogenesis inhibitor. Exp Cell Res. 2010;316:775-88

45. Jonasch E, Haluska FG. Interferon in oncological practice: review of interferon biology, clinical applications, and toxicities. Oncologist 2001;6:3455

46. Vasudev NS, Reynolds AR. Anti-angiogenic therapy for cancer: current progress, unresolved questions and future directions. Angiogenesis 2014;17:471-494

47. Allegra CJ, Yothers G, O'Connell MJ, Sharif S, Petrelli NJ, Lopa SH, Wolmark N. Bevacizumab in stage II-III colon cancer: 5-year update of the National Surgical Adjuvant Breast and Bowel Project C-08 trial. J. Clin. Oncol 2013;31:359-364

48. Wentink MQ, Huijbers EJ, de Gruijl TD, Verheul HM, Olsson AK, Griffioen AW. Vaccination approach to anti-angiogenic treatment of cancer. Biochim Biophys Acta 2015;1855:155-171

49. Okaji Y, Tsuno NH, Tanaka M, Yoneyama S, Matsuhashi M, Kitayama J, Saito S, Nagura Y, Tsuchiya T, Yamada J, Tanaka J, Yoshikawa N, Nishikawa T, Shuno Y, Todo T, Saito N, Takahashi K, Nagawa H. Pilot study of antiangiogenic vaccine using fixed whole endothelium in patients with progressive malignancy after failure of conventional therapy. Eur J Cancer 2008;44:383-390

50. Li Z, Yang S, Chang T, Cao X, Shi L, Fang G. Anti-angiogenesis and anticancer effects of a plasmid expressing both ENDO-VEGI151 and small interfering RNA against survivin. Int J Mol Med. 2012;29:485-490

51. Yang X, Wu XZ. Main Anti-tumor Angiogenesis Agents Isolated From Chinese Herbal Medicines. Mini Rev Med Chem. 2015;15:1011-1023

52. Schipani E, Wu C, Rankin EB, Giaccia AJ (2013) Regulation of Bone Marrow Angiogenesis by Osteoblasts during Bone Development and Homeostasis. Front Endocrinol (Lausanne) 4:article 85

53. Medinger M, Mross K. Clinical trials with antiangiogenic agents in hematological malignancies. J Angiogenes Res 2010;2: 10

54. Vacca A, Ribatti D, Roncali L, Ranieri G, Serio G, Silvestris F, Dammacco F. Bone marrow angiogenesis and progression in multiple myeloma. Br J Haematol 1994;87:503-508

55. Rajkumar SV, Leong T, Roche PC, Fonseca R, Dispenzieri A, Lacy MQ, Lust JA, Witzig TE, Kyle RA, Gertz MA, Greipp PR. Prognostic value of bone marrow angiogenesis in multiple myeloma. Clin Cancer Res 2000;6:3111-3116

56. Yetgin S, Yenicesu I, Cetin M, Tuncer M. Clinical importance of serum vascular endothelial and basic fibroblast growth factors in children with acute lymphoblastic leukemia. Leuk Lymphoma 2001;42:83-88

57. Medinger M, Skoda R, Gratwohl A, Theocharides A, Buser A, Heim D, Dirnhofer S, Tichelli A, Tzankov A. Angiogenesis and vascular endothelial growth factor-/receptor expression in myeloproliferative neoplasms: correlation with clinical parameters and JAK2-V617F mutational status. Br J Haematol 2009;146:150-157

58. Dias S, Hattori K, Zhu Z, Heissig B, Choy M, Lane W, Wu Y, Chadburn A, Hyjek E, Gill M, Hicklin DJ, Witte L, Moore MA, Rafii S. Autocrine stimulation of VEGFR-2 activates human leukemic cell growth and migration. J Clin Invest 2000;106:511-521

59. De Raeve H, Van Marck E, Van Camp B, Vanderkerken K. Angiogenesis and the role of bone marrow endothelial cells in haematological malignancies. Histol Histopathol 2004;19:935950

60. Hussong JW, Rodgers GM, Shami PJ. Evidence of increased angiogenesis in patients with acute myeloid leukemia. Blood 2000;95:309-313

61. Frater JL, Kay NE, Goolsby CL, Crawford SE, Dewald GW, Peterson LC. Dysregulated angiogenesis in B-chronic lymphocytic leukemia: Morphologic, immunohistochemical, and flow cytometric evidence. Diagn Pathol 2008;3:16

62. Kruizinga RC, de Jonge HJ, Kampen KR, Walenkamp AM, de Bont ES. Vascular 
endothelial growth factor A isoform mRNA expression in pediatric acute myeloid leukemia. Pediatric Blood and Cancer 2011;56:294-297

63. Mourah S, Porcher R, Lescaille G, Rousselot P, Podgorniak MP, Labarchède G, Naimi B, Medioni J, Dombret H, Calvo F. Quantification of VEGF isoforms and VEGFR transcripts by qRT-PCR and their significance in acute myeloid leukemia. Int $\mathrm{J}$ Biol Markers 2009;24:22-31

64. Schmidt T, Carmeliet P. Angiogenesis: A Target in Solid Tumors, Also in Leukemia? Hematology Am Soc Hematol Educ Program 2011;2011:1-8

65. Schneider P, Dubus I, Gouel F, Legrand E, Vannier $\mathrm{P}$ and Vasse $\mathrm{M}$. What Role for Angiogenesis in Childhood Acute Lymphoblastic Leukaemia? Adv Hematol 2011;2011:274628

66. Salven P, Orpana A, Teerenhovi L, Joensuu H. Simultaneous elevation in the serum concentrations of the angiogenic growth factors VEGF and bFGF is an independent predictor of poor prognosis in non-Hodgkin lymphoma: a single institution study of 200 patients. Blood 2000;96:3712-3718

67. Faderl S, Do KA, Johnson MM, Keating M, O'brien S, Jilani I, Ferrajoli A, Ravandi-Kashani F, Aguilar C, Dey A, Thomas DA, Giles FJ, Kantarjian HM, Albitar M. Angiogenic factors may have a different prognostic role in adult acute lymphoblastic leukemia. Blood 2005;106:43034307

68. Zhao Y, Adjei AA. Targeting Angiogenesis in Cancer Therapy: Moving Beyond Vascular Endothelial Growth Factor. Oncologist 2015;20:660-673

69. Los M, Roodhart JML, Voest EE. Target Practice: Lessons from Phase III Trials with Bevacizumab and Vatalanib in the Treatment of Advanced Colorectal Cancer. The Oncologist 2007;12:443450

70. Van Cutsem E, Lambrechts D, Prenen H, Jain RK, Carmeliet P. Lessons from the adjuvant bevacizumab trial on colon cancer: what next? J Clin Oncol 2011;29:1-4

71. Fala L. Cyramza (Ramucirumab) Approved for the Treatment of Advanced Gastric Cancer and Metastatic Non-Small-Cell Lung Cancer. Am Health Drug Benefits 2015;8 (Spec Feature):4953

72. Ciombor KK, Berlin J. Aflibercept--a decoy VEGF receptor. Curr Oncol Rep. 2014;16:368

73. Hay N, Sonenberg N. Upstream and downstream of mTOR. Genes Dev 2004; 18:1926-1945

74. Paplomata E, Zelnak A, O'Regan R. Everolimus: side effect profile and management of toxicities in breast cancer. Breast Cancer Res Treat 2013;140:453-462

75. Vazakidou ME, Magkouta S, Moschos C, Psallidas I, Pappas A, Psarra K, Kalomenidis I. Temsirolimus targets multiple hallmarks of cancer to impede mesothelioma growth in vivo. Respirology. 2015;20:1263-1271

76. Dinney CP, Bielenberg DR, Perrotte P, Reich R, Eve BY, Bucana CD, Fidler IJ. Inhibition of basic fibroblast growth factor expression, angiogenesis, and growth of human bladder carcinoma in mice by systemic interferon-alpha administration. Cancer Res 1998;58:808-814

77. Singh RK, Gutman M, Bucana CD, Sanchez R, Llansa N, Fidler IJ. Interferons alpha and beta down-regulate the expression of basic fibroblast growth factor in human carcinomas. Proc Natl Acad Sci U S A 1995;92:4562-4566

78. Grignol VP, Olencki T, Relekar K, Taylor C, Kibler A, Kefauver C, Wei L, Walker MJ, Chen HX,5 Kari Kendra,2 and William E. Carson, III. A Phase II trial of Bevacizumab and High Dose Interferon Alpha-2B in Metastatic Melanoma. J Immunother 2011; 34: 509-515

79. Albiges L, Gizzi M, Carton E, Escudier B. Axitinib in metastatic renal cell carcinoma. Expert Rev Anticancer Ther. 2015;15:499-507

80. Nielsen $\mathrm{OH}$, Grimm D, Wehland M, Bauer J, Magnusson NE. Anti-Angiogenic Drugs in the Treatment of Metastatic Renal Cell Carcinoma: Advances in Clinical Application. Curr Vasc Pharmacol 2015;13:381-391

81. Alonso-Gordoa T, Díez JJ, Durán M, Grande E. Advances in thyroid cancer treatment: latest evidence and clinical potential. Ther Adv Med Oncol. 2015;7:22-38

82. Verweij J, Sleijfer S. Pazopanib, a new therapy for metastatic soft tissue sarcoma. Expert Opinion on Pharmacotherapy 2013;14:929-935

83. Tampellini M, Sonetto C, Scagliotti GV. Novel anti-angiogenic therapeutic strategies in colorectal cancer. Expert Opin Investig Drugs. 2016 May;25(5):507-20

84. Wilhelm SM, Adnane L, Newell P, Villanueva A, Llovet JM, Lynch M. Preclinical overview of sorafenib, a multikinase inhibitor that targets both Raf and VEGF and PDGF receptor tyrosine kinase signaling. Mol Cancer Ther 2008;7:3129-3140

85. Gauthier A. Role of sorafenib in the treatment of advanced hepatocellular carcinoma: An update. Hepatol Res 2013;43:147-154

86. Gan HK, Seruga B, Knox JJ. Sunitinib in solid tumors. Expert Opin Investig Drugs 2009;18:821834

87. Abdelraouf F, Smit E, Hasan B, Menis J, Popat S, van Meerbeeck JP, Surmont VF, Baas P, O'Brien M. Sunitinib (SU11248) in patients with chemo naive extensive small cell lung cancer or who have a 'chemosensitive' relapse: A single-arm phase II study (EORTC-08061). Eur J Cancer 2015;54:3539

88. Perri F, Pezzullo L, Chiofalo MG, Lastoria S, Di Gennaro F, Scarpati GD, Caponigro F. Targeted therapy: a new hope for thyroid carcinomas. Crit Rev Oncol Hematol. 2015;94:55-63 
89. Tageja N. Lenalidomide - current understanding of mechanistic properties. Anticancer Agents Med Chem 2011;11:315-326

90. Kim JH, Scialli AR. Thalidomide: The Tragedy of Birth Defects and the Effective Treatment of Disease. Toxicol Sci 2011;122:1-6

91. Singhal S, Mehta J. Thalidomide in cancer. Biomed Pharmacother 2002;56:4-12

92. Gacche RN. Compensatory angiogenesis and tumor refractoriness. Oncogenesis 2015;4:e153

93. Qian CN, Tan MH, Yang JP, Cao Y. Revisiting tumor angiogenesis: vessel co-option, vessel remodeling, and cancer cell-derived vasculature formation. Chin J Cancer 2016;35:10

94. Donnem T, Hu J, Ferguson M, Adighibe O, Snell C, Harris AL, Gatter KC, Pezzella F. Vessel cooption in primary human tumors and metastases: an obstacle to effective anti-angiogenic treatment? Cancer Med 2013;2:427-436

95. Djonov V, Schmid M, Tschanz SA, Burri PH. Intussusceptive angiogenesis: its role in embryonic vascular network formation. Circ Res 2000;86:286-292

96. Maniotis AJ, Folberg R, Hess A, Seftor EA, Gardner LM, Pe'er J, Trent JM, Meltzer PS, Hendrix MJ. Vascular channel formation by human melanoma cells in vivo and in vitro: vasculogenic mimicry. Am J Pathol 1999; $155: 739-752$

97. Pezzella F, Gatter K, Qian CN. Twenty years after: the beautiful hypothesis and the ugly facts. Chin J Cancer 2016;35:22

98. Dey N, De P, Brian LJ. Evading anti-angiogenic therapy: resistance to anti-angiogenic therapy in solid tumors. Am J Transl Res 2015;7:1675-1698

99. Liu S and Kurzrock R. Toxicity of targeted therapy: Implications for response and impact of genetic polymorphisms. Cancer Treat Rev 2014;40:883-891

100. Bécouarn Y, Cany L, Pulido M, Beyssac R, Texereau P, Le Morvan V, Béchade D, Brunet R, Aitouferoukh S, Lalet C, Mathoulin-Pélissier S, Fonck M, Robert J. FOLFIRI(R) and Bevacizumab in first-line treatment for colorectal cancer patients: safety, efficacy and genetic polymorphisms. BMC Res Notes 2014;7: 260

101. Verheul HM and Pinedo HM. Possible molecular mechanisms involved in the toxicity of angiogenesis inhibition. Nat Rev Cancer 2008;7:475-485

102. Elice F, Rodeghiero F. Side effects of antiangiogenic drugs. Thromb Res 2012;129 Suppl 1:S50-S53

103. Takada $\mathrm{S}$, Hoshino $\mathrm{Y}$, Ito $\mathrm{H}$, Masugi $\mathrm{Y}$, Terauchi T, Endo K, Kimata M, Furukawa J, Shinozaki H, Kobayashi K, Ogata Y. Extensive bowel necrosis related to bevacizumab in metastatic rectal cancer patient: a case report and review of literature. Jpn J Clin Oncol 2015;45:286-290
104. Mross K, Büchert M, Frost A, Medinger M, Stopfer P, Studeny M, Kaiser R. Vascular effects, efficacy and safety of nintedanib in patients with advanced, refractory colorectal cancer: a prospective phase I subanalysis. BMC Cancer 2014;14:510-520

105. Crafton SM, Salani R. Beyond Chemotherapy: An Overview and Review of Targeted Therapy in Cervical Cancer. Clin Ther 2016;38:449-58

106. Taketomi A. Clinical trials of antiangiogenic therapy for hepatocellular carcinoma. Int $\mathrm{J}$ Clin Oncol 2016;21:213-218

107. Jayson GC, Kerbel R, Ellis LM, Harris AL. Antiangiogenic therapy in oncology: current status and future directions. Lancet 2016 (in press). 